\title{
Transiçõos do corpo à voz, à procura do outro: em direção ao ator bilíngue
}

Graça dos Santos

Professora associada na Universidade Paris Ouest Nanterre La Défense (EA 369 Etudes Romanes), diretora do Departamento de Estudos Lusófonos e investigadora no CRILUS (Centre de recherches interdisciplinaires sur le monde lusophone).

E-mail: dos-santos.graca@wanadoo.fr

Resumo: A autora investiga, neste artigo, os fenômenos e consequências decorrentes do deslocamento geográfico sobre o processo de reconstrução da linguagem, analisando a influência da língua mãe em confronto com o aprendizado e uso de um novo idioma e correlacionando este processo à própria construção da identidade pessoal e cultural do indivíduo.

Palavras-chave: Linguagem, cultura, linguística, identidade.
Abstract: In this article the author investigates the phenomena and consequences of geographic displacement on the process of language reconstruction, analyzing the influence of the mother tongue and its learning, and the use of a new language, correlating this process to the individual's own construction of his/her personal and cultural identity.

Keywords: Language, culture, linguistics, identity.

Quando se encena Hamlet,

é a voz dos ancestrais

que fala através de nosso corpo.

No teatro, nós tentamos criar um espaço para que essas vozes invisíveis sejam ouvidas

em uma sociedade materialista que acredita somente na existência daquilo que ela pode ver, tocar ou vender ${ }^{1}$.

\section{A VOZ, EXTENSÃO DO CORPO NO ESPAÇO}

Para o filho dos humanos, o nascimento é a mise en voix ${ }^{2}$, é o grito primal ou a palavra de vida... Sua voz não se apagará senão quando ele der o seu último sopro: é o último suspiro ou o silêncio da morte... A sede de ar que faz gritar o moribundo é a mesma que faz gritar o recém-nascido: entre esses dois gritos do ser, há o tempo da vida, o percurso de uma consciência, a trama de um destino. Fazer ouvir sua voz, balbuciar, falar, cantar, rir ou chorar, é viver como sujeito no mundo dos homens ${ }^{3}$.

Recebido: 25/01/2012

Aprovado: 16/04/2012

1. SELLARS, Peter. Etre acteur, jouer, agir. In: FERAL, Josette. Les chemins de l'acteur, former pour jouer. Montréal: Editions Québec Amérique, 2011. p. 83.

2. A interpretação feita através da voz, a leitura dramática, a declamação.

3. CASTARÈdE, Marie-France. La voix et ses sortillèges [A voz e seus sortilégios]. Paris: Les belles lettres, 1991. p. 11. 
comunicação \& educação • Ano XVII • número 2 • jul/dez 2012

4. RUNTZ-CHRISTIAN, Edmée. Enseignant et comédien, un même métier? [Professor e ator uma mesma ocupação?] Issy-les-Moulineaux: ESF Editeur, 2000.

5. PAVIS, Patrice. Dictionaire du théâtre [Dicionário do Teatro]. Paris: Armand Colin/VUEF, 2002

6. CORVIN, Michel. Dictionnaire encyclopédique du théâtre à travers le monde [Dicionário enciclopédico do teatro em todo o mundo]. Paris: Editions Bordas/SEJER 2008. p. 1424

7. BERNARD, Michel RYNGAERT, Jean-Pierre. L'improvisation [A improvisação]. In: LALLIAS, Jean-Claude, ${ }_{\text {, JACQUES }}$ Lassalle; LORIOL, Jean-Pierre, Dir. Le théâtre et l'école. Histoire et perspective d'une relation passionnée $[0$ teatro e a escola. História e perspectiva de uma relação passional]. Cahiers de I'ANRAT, Arles, Actes Sud, n. 11, 2002, p. 114

8. BENECH, Bernard. La parole offerte; quelques réflexions sur la voix au théâtre $[\mathrm{O}$ discurso oferecido; algumas reflexões sobre a voz no teatro]. In: Art et thérapie [Arte e terapia], n. 68/69, Les champs de la voix [Os campos da voz], p. 64

9. JOUVET, Louis. Le comédien désincarné $[O$ ator desencarnado]. Paris: Flammarion/Champs, 2009
Esta citação, ao mesmo tempo poética e filosófica, é uma bela maneira de resumir a essência da voz e o seu papel na vida de cada um. De fato, se é determinante para o indivíduo, ganha, por sua vez, todo o seu sentido quando entendida pelo outro, sendo indispensável à comunicação sem a qual a sociedade não teria fundamento. Este "viver como sujeito no mundo dos homens", ao qual Marie-France Castarède associa diversas atividades oferecidas pela voz, varia mediante os períodos da vida. Nossa reflexão seguirá esta prática realizada entre dois espaços fundamentais: a sala de espetáculos e a sala de aula. "Professor e ator, um mesmo ofício?". O paralelo não é novo e, além da questão do "uso profissional da voz" na confluência de dois campos de atividade, exploraremos suas intersecções à luz de um denominador comum: a vontade de cativar um auditório.

Se a voz é o instrumento imediato desta pesquisa, ela não pode ser dissociada do corpo do qual é extensão ${ }^{5}$. A abordagem nem sempre foi evidente, já que, originalmente, o corpus latino nomeava a dimensão física do corpo humano como matéria e objeto da visão, enquanto a voz, ligada à audição e à respiração, era sentida como imaterial e incorporada à alma ${ }^{6}$. Parece evidente, porém, que a voz é produção física e corporal - embora a oposição reapareça na esfera da comunicação verbal, quando a voz se transforma em veículo separado da língua. Nosso enfoque tenderá a refletir a unidade das três instâncias corpo/voz/palavra - em que o corpo será considerado "potência vocal articulante e motora"7.

\section{O DESLOCAMENTO DE SABERES: DO ISOLAMENTO DA VOZ À PREEMINÊNCIA DO TEXTO}

Durante muito tempo, a arte do ator centrou-se na "declamação". Procurava-se produzir "atletas do verbo", cuja perfeição dependia da originalidade do timbre e da escolha de inflexões. O comportamento físico ligado à palavra era codificado e ensinado. O objetivo dessa formação, hoje considerada obsoleta, era produzir formas de jogo estereotipadas e atrair a atenção sobre os elementos constitutivos da linguagem - vogais, consoantes, o ritmo e a claridade do discurso e, em particular, o texto em verso ${ }^{8}$. Não faltam vestígios de interpretações inesquecíveis de "monstros sagrados" do cenário. "Sua voz parecia flutuar ao redor dela e seus olhos pareciam por vezes segui-la. Segundo o texto, ela cantava, ela martelava, ela apressava a cadência como um galope que rolava, subia, batia e parava em um silêncio que estourava súbito em um soluço repetido. Então uma espécie de canto voluntariamente monótono que terminava em um alvoroço de uma sinceridade infinita ou em um lampejo de raiva, de revolta ou de sofrimento que ela não abandonava até o final do período. Nunca um falha no crepitar de palavras, de gritos, de lágrimas", concluiu Louis Jouvet $^{9}$, com uma metáfora que evoca tanto a estrela do teatro francês, Sarah Bernhardt, quanto a entonação e as intenções de sua voz. 


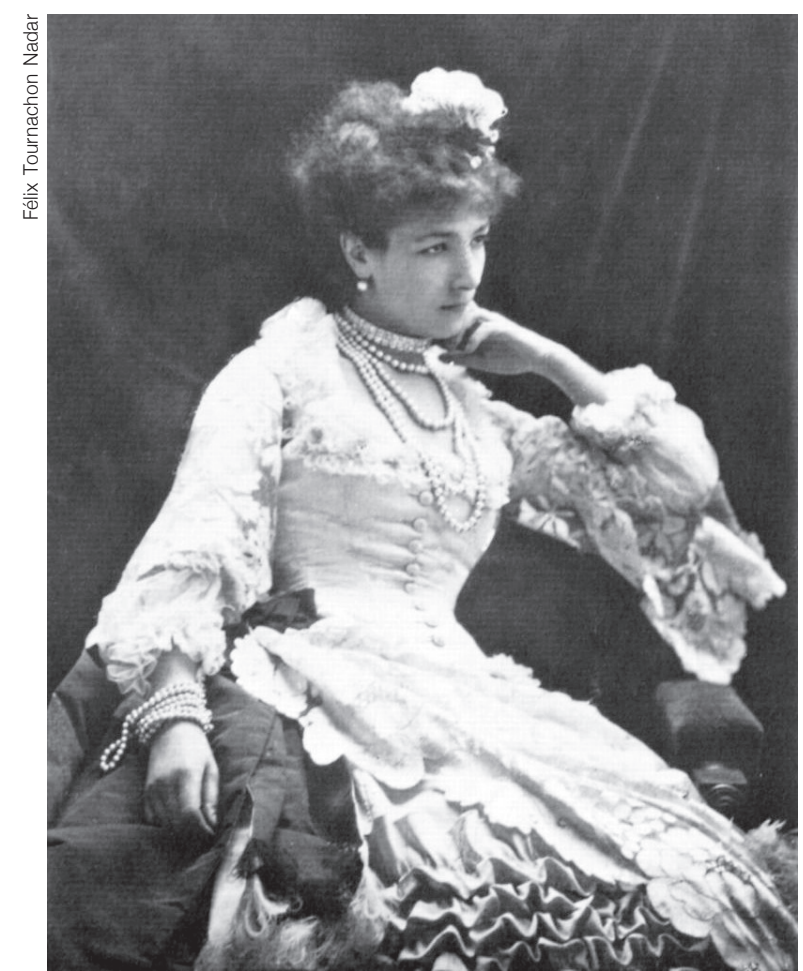

Sarah Bernhardt foi assim descrita por Louis Jouvet: "Sua voz parecia flutuar ao redor dela e seus olhos pareciam por vezes segui-la. Nunca um falha no crepitar de palavras, de gritos, de lágrimas."

Da mesma forma, outras vozes se tornaram componentes de uma personalidade original ou ligadas a características gestuais bastante estudadas. A aparição da mise en scène ${ }^{10}$ focaria a atenção no corpo e nos recursos cênicos, permitindo que a palavra se voltasse à emoção além do sentido. O campo da experimentação das práticas vocais do ator, dessa forma, expandiria o horizonte de vários "ismos" (como futurismo, expressionismo e dadaísmo). Ao longo do século XX, os diretores de teatro extraíram da voz o que possui de mais individual, buscando possibilidades contidas na linguagem e restituindo capacidades sonoras que a expressão do pensamento poderia fazer minguar.

O desaparecimento da declamação, dessa forma, dá origem a duas correntes: de isolamento da voz, fazendo dela um objeto de pesquisas e experiências; e de preeminência do texto. Artaud e Grotowski, passando por Julian Beck e Judith Malina ou, ainda, por Eugenio Barba, tentaram, sozinhos ou não, recuperar a origem da linguagem através da cerimônia e do ritual. A voz, proferida e projetada, se torna um gesto do corpo e contribui para o despertar de outras vozes. Próxima do grito e considerada em sua expressão inarticulada, é também objeto pulsional, fantástico e prazeroso.

De outro lado, a partir de 1970, na França, a classe de interpretação substituiu a de declamação nos conservatórios. Os cursos de dicção passaram a ter 
comunicação \& educação • Ano XVII • número 2 • jul/dez 2012

11. ZAEPFFEL, Alain. Quelques notes sur la déclamation [Algumas notas sobre a declamação] In: LALLIAS, Jean-Claude; LASSALLE, Jacques; LORIOL, Jean-Pierre, Dirop. Cit., p. 151

12. Apud ZAEPFFEL, Alain, op. cit., p. 152.

13. BARBA, Eugenio L'essence du théâtre $[A$ essência do teatro]. In FÉRAL, Josette. Les chemins de l'acteur, former pour jouer [Os caminhos do ator, treinados para atuar]. Montreal: Editions Québec Amérique, 2001 p. 55.

14. Retirado do resumo sobre o grupo Odin Teatret, escrito pelo autor.

15. HUSTON, Nancy. Nord perdu [Norte perdido]. Arles: Actes Sud, 1999.

16. Ibid., p. 19. como foco a língua, tirando a voz do cerne do ensino. O cantor e professor de música Alain Zaepffel observa que, nesse momento, se aprofunda "o esquecimento dos elos em que a respiração fazia coincidir com a frase, a voz e a pontuação, o sistema fonético da língua e até com o que compõe o ritmo: os acentos"; tudo isso em detrimento do "conhecimento prolongado do instrumento vocal reduzido à transparência do personagem ou a um simples resíduo da fala". Constata-se, no entanto, que a voz retorna sob a forma de sintoma para muitos jovens, vítimas de disfonias disfuncionais ${ }^{11}$. Ele lamenta a cisão entre $o$ ensino da música e da arte dramática que profissionais de teatro se esforçaram em compensar em seu ensino - como no caso de Antoine Vitez, por exemplo, que evoca "o canto falado da língua francesa"12.

\section{A MUTILAÇÃO DA LÍNGUA}

É evidente que cada língua possui musicalidade, ritmo e acentuação próprios. Sem conhecer línguas estrangeiras, basta prestar atenção às outras culturas para ouvir as "partituras" de idiomas cujos sons nos parecem estrangeiros.

"Toda forma de exílio é como um veneno, se não mata, fortalece", diz Eugenio Barba, referindo-se à história de seu grupo de teatro Odin Teatret, que define como fruto de duas exclusões: "a exclusão do meio teatral e a mutilação da língua"13. Sublinhemos a relação estabelecida por Barba entre exílio, língua e teatro no momento de evocar a trajetória da trupe ${ }^{14}$ que se isolou da vida teatral e de um mundo de língua inteligível para encontrar o que consideravam o fundamento do teatro. "Exclusão" e "mutilação" evocam dor e separação, enquanto o paralelo com "veneno" remete ao perigo de envenenamento físico e mental que acarreta o transporte, voluntário ou não, de um ser humano extraído de seu lugar de nascimento para um espaço desconhecido e, portanto, potencialmente agressivo e mortífero. "Esta situação de inferioridade e esta amputação, estas coerções, nós as derrubamos e fizemos crescer dessa poeira uma atitude de orgulho, de honra, de recusa: nossas fontes de força", conclui o diretor.

\section{INCAPACIDADE DE SEMELHANÇA ABSOLUTA}

Esta relação tripartida está no centro de Nord perdu ${ }^{15}$, em que Nancy Huston evoca os meandros do caminho entre as duas línguas que constituem seu percurso do Canadá, seu país de nascimento, à França, onde estabeleceu domicílio e cuja língua escolheu para formular uma obra reconhecida. "O expatriado descobre de maneira consciente (e às vezes dolorosa) certo número de realidades que modelam, mais frequentemente sem o nosso consentimento, a condição humana"16 diz ela, ampliando sua experiência pessoal àquela dos viajantes de longo prazo - aqui nomeados "exilados" ou "expatriados", termos cujo prefixo enfatiza o caráter de exterioridade e seu potencial de privação. 
Transições do corpo à voz, à procura do outro - Graça dos Santos

Não podemos evitar de acrescentar, à definição "de expulsão", os migrantes clandestinos. É evidente que, de acordo com o meio social do qual somos oriundos, a experiência do deslocamento difere tanto no sentimento vivido como no tratamento dispensado pelas autoridades - ou ainda nas representações com que é divulgado.

Escolher na idade adulta, por conta própria, de maneira individual para não dizer caprichosa, deixar o seu país e conduzir o restante de sua existência em uma cultura e uma língua até então estrangeiras, é aceitar se estabelecer para sempre "na imitação, no faz de conta, no teatro"17.

O sotaque é habitualmente percebido como a presença de um depósito - paladar marcante, odor impregnado, agradável ou desagradável, evocativo ou misterioso, o rastro ou o indício alhures da língua, de um fora de campo que permanece aberto nos bastidores da fala, de um pano de fundo presente na profundidade do campo. O sotaque revela, denuncia, trai um passageiro clandestino, uma língua fantasma, o fantasma de uma língua, escondidos na segunda língua que o locutor atualiza. Esta presença é aquela de um morto, ou somente a de um ausente, a presença de um passado ou de um "inatual" na atualização do discurso? O sotaque é ao mesmo tempo uma forma de memória e a marca de uma diferença, a incapacidade de semelhança absoluta, de mimetismo perfeito, ao ideal camaleônico de camuflagem ${ }^{18}$.

\section{REPRODUZIR AQUILO QUE ACREDITAMOS OUVIR}

Só podemos imitar aquilo que ouvimos ou, mais precisamente, aquilo que acreditamos ouvir. No domínio da audição, a memória é "original", remetendo-nos às primeiras lembranças vocais e, em particular, à voz da mãe, que já transmite a língua materna. O mecanismo de aquisição linguística é ativo bem antes da pronúncia da primeira palavra. "A primeira tarefa da criança será reconhecer unidades de significado, palavras, no fluxo de som que a rodeia" ${ }^{\text {. }}$. Pesquisas provam que bebês com poucos dias de vida são capazes de distinguir a diferença entre fonemas próximos; da mesma forma, são sensíveis à prosódia e reconhecem a voz da mãe, assim como as palavras de sua língua materna entre outras línguas. Esta capacidade, porém, desaparece progressivamente e, em cerca de 10-12 meses, eles concentram exclusivamente sobre a língua que os circunda.

Aos 11 ou 13 meses, a primeira palavra reconhecível é pronunciada - e, a partir de 18 meses, o vocabulário aumenta rapidamente. Se o período de 0 a 3 anos é considerado primordial para a aquisição da linguagem, a criança permanece propícia a esta aquisição até a puberdade - periodização que condiciona, portanto, a introdução de uma segunda língua, assim como "o mimetismo perfeito" necessário ao bilinguismo. "Se o contato com uma segunda língua começa depois da idade de 6 anos, os mecanismos de aprendizagem, diferentes dos implicados na aquisição da linguagem, culminam em um bilinguismo tardio” ${ }^{20}$. As competências do aprendizado bilíngue, porém, evoluem ao longo

17. Ibid., p. 32.

18. FLEISCHER, Alain. L'accent, une langue fantôme $[O$ sotaque, uma língua fantasma]. Paris: Editions du Seuil, 2005, p. 78.

19. ABDELILAH-BAUER, Barbara. Le défi des enfants bilingues. Grandir et vivre en parlant plusieurs langues $[O$ desafio das crianças bilíngues. Crescer e viver em ambientes multilingues]. Paris: Editions La Découverte, 2006. p. 12.

20. Ibid., p. 27. 


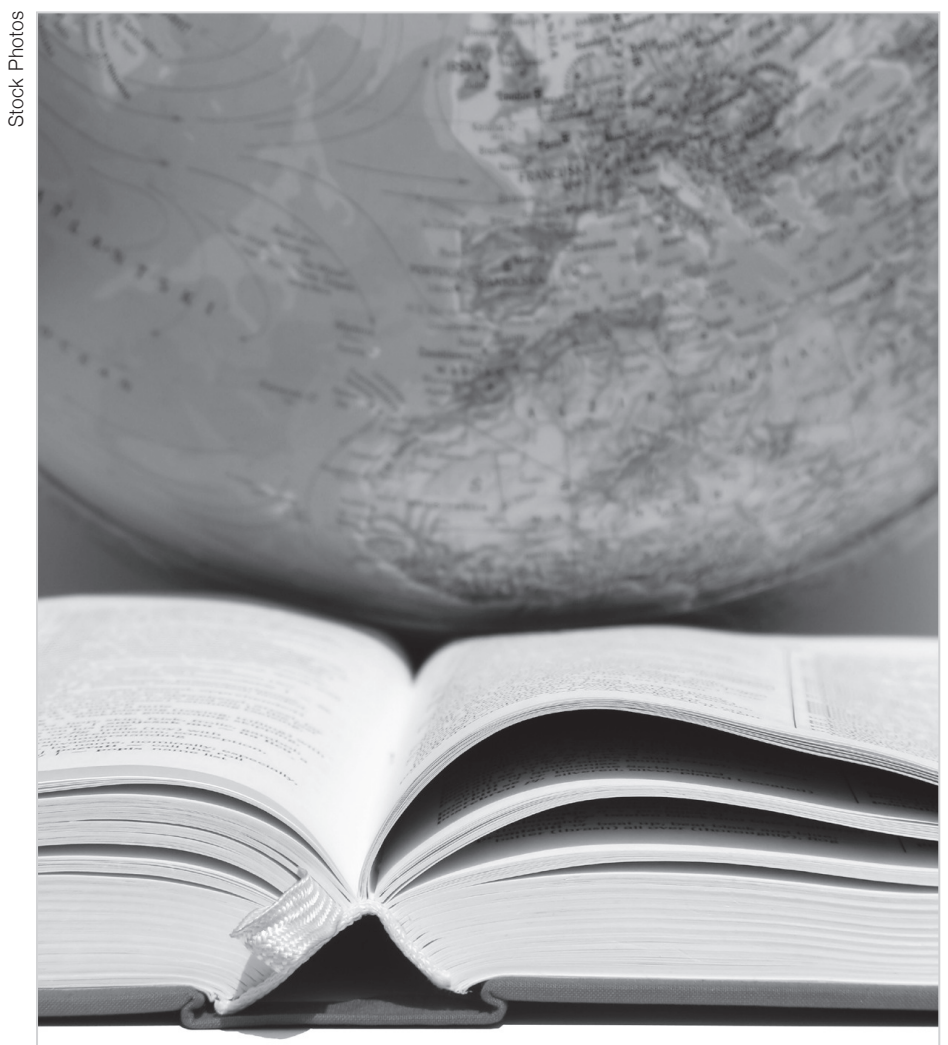

No domínio da audição, a memória nos remete às primeiras lembranças vocais, que já transmitem a língua materna. O mecanismo de aquisição linguística é ativado bem antes

da pronúncia da primeira palavra.

do tempo em cada idioma, conforme a idade. O bilinguismo dito "equilibrado" é pouco comum, pois em uma sociedade monolíngue não usamos nunca duas línguas com o mesmo grau de intensidade.

\section{A REALIDADE DILATADA DO BILÍNGUE}

Ser bilíngue é, então, desenvolver ouvido e olhar para escutar e ver duplamente.

Em uma situação de comunicação, o bilíngue possui, por assim dizer, "antenas" suplementares que lhe indicam qual língua ele deve falar com determinada pessoa e em qual momento ele pode mudar de língua. Esta sensibilidade acrescida à situação de interação se manifesta por uma grande atenção destinada às necessidades do interlocutor, a uma percepção mais sutil dos indícios verbais e não verbais de uma comunicação ${ }^{21}$.

A criança bilíngue desenvolve de maneira precoce uma consciência de diferenças culturais que a monolíngue não necessariamente possui. Mas essa 
Transições do corpo à voz, à procura do outro • Graça dos Santos

dilatação, se não é enriquecimento, pode também atordoar. Nancy Huston diz ter "perdido o norte" - para ela, o extremo norte do Canadá -, assim como seus referenciais de orientação. "A estraneidade é uma metáfora que precisa do outro", diz ela, determinando que "nós somos dois, cada um de nós, ao menos dois". Ela explica a confusão à qual pode conduzir a binariedade de quem chama de "bilíngue expatriado".

Quando os monolíngues percebem um objeto familiar, o seu nome lhe vem automaticamente na mente. Para mim, o nome que vem depende da língua na qual eu estou em vias de refletir. Às vezes uma das palavras me vem, enquanto é da outra que eu preciso. Às vezes as duas afloram simultaneamente ou em sucessão. Mas às vezes isso se complica, isso se embrulha, se bloqueia e eu me arrancaria os cabelos. [...] Algumas palavras simplesmente se recusam, seja na língua materna ou na adotiva, a fazer o trajeto do meu cérebro até os meus lábios - palavras que eu não acho jamais nos momentos em que necessito delas ${ }^{22}$.

Este é o fenômeno terrível: saber que há vocábulos próprios para expressar uma ideia e não dispor deles no momento requisitado. Procuramos, então, soluções de preenchimento para nos socorrer em emergências. Uma reserva de vocábulos equivalentes, ou sinônimos, permanece na memória, ainda que não sejam totalmente satisfatórios.

\section{ENCONTRAR A MEMÓRIA DO JOGO VERBAL}

Se o estrangeiro "é condenado à imitação consciente", para imitar é preciso observar, na busca de reproduzir o comportamento físico e vocal do outro. A tarefa não se separa do trabalho do ator, a não ser pela consciência dos processos desencadeados. Aprender a língua do outro é mexer com essa língua, voz e respiração. Eis o que nos distancia do aprendizado de línguas estrangeiras que os bancos de escola proporcionam: acostumaram-nos a aprender sentados e com uma caneta na mão. Instintivamente, aprender é uma memória cinestésica que reclama os gestos manuais e a visão, muito mais que a audição, dominante na memória antes da tentativa de reprodução do som. De acordo com a experiência do aprendizado na escola primária, cada encontro com uma nova língua será influenciado por esse começo fundador.

[...] compreender ou utilizar a linguagem requer o constante recurso aos órgãos sensoriais (o ouvido, o olho...), e aos comandos motores (músculos da língua ou da mão, respiração...). Uma sala de aula é, então, um vasto reservatório ou laboratório de linguagem sensorial, cheia de ruídos de palavras ${ }^{23}$.

A fim de evitar o retorno das tensões eventuais das primeiras experiências e, ao mesmo tempo, dar ao ouvido o seu lugar fundamental, é adequado inicialmente escutar a nova língua, ao invés de passar à leitura como primeiro passo.

"A criança aprende muitas coisas através do jogo; por analogia, nós podemos dizer que a criança aprende a falar jogando; nós podemos, por fim,

22. HUSTON, op. cit.

23. ZEKRI-HURSTEL, Régine. Un nouveau regard sur l'élève; langage, gestes et postures [Um novo olhar sobre o aluno; linguagem, gestos e posturas]. Rodez: Editions du Rouergue, 2001. 
comunicação \& educação • Ano XVII • número 2 • jul/dez 2012

24. ERARD, Yves. Faire entendre sa voix [Faça ouvir a sua voz]. Multitudes, n. 42, automne 2000. p. 191.

25. RYNGAERT, Jean-Pierre. Jouer, représenter (Pratiques dramatiques et formation) [Jogar, representar (práticas dramáticas e formação)]. Paris: CEDIC, 1985. p. 39. 26. ERARD, op. cit., p. 194.

27. BOURDIEU, Pierre. Méditations pascaliennes [Meditações pascalianas]. Paris: Seuil, 1997. Apud ERARD, Yves, op. cit., p. 195.

28. STEIGER, André. Le jeu comme transparence [O jogo como transparência], In: FÉRAL, Josette. Les chemins de l'acteur, former pour jouer [Os caminhos do ator, treinado para atuar]. Montréal: Editions Québec Amérique INC, 2001. p. 113 chamar este tipo de jogo de jogo verbal ou um jogo de linguagem" ${ }^{24}$. Desta memória é conveniente se valer: no jogo da infância, com o corpo em movimento, cadeiras e mesas são empurradas e se estabelece um ateliê de idiomas, ao longo do qual, através de uma abordagem bilíngue e a partir de uma língua comum de comunicação, tentamos compreender o momento de passagem de uma língua à outra.

\section{FAZER OUVIR A SUA VOZ / A VOZ REMINISCENTE DAS ORIGENS}

A situação é próxima à de uma oficina de arte dramática, o que, para os participantes, pode ser confuso - uma vez que tenham, inicialmente, a expectativa de somente escutar, escrever e, talvez, repetir algumas palavras da nova língua, ao invés de se confrontar com exercícios de aquecimento e relacionamento com os outros membros do grupo. Por vezes vemos crises de risos ou a recusa a participar, pois o jogo corporal fragiliza os participantes e dá um poder exorbitante a quem dá as instruções.

Os discursos na moda sobre o lugar do corpo e as piadas rituais sobre os ateliês de teatro como lugares onde "se toca" aumentam as dificuldades. O corpo entra em jogo junto com todos os tabus que o acompanham, com o peso legítimo das inquietudes e dos desejos ${ }^{25}$.

Pouco a pouco, no entanto, o jogo da linguagem incita a "fazer lugar" no grupo criado e a fazer ouvir a sua voz. Rapidamente, enquanto ela é exprimida, fica evidente que a expressão caminha lado a lado com a escuta: "minha voz possui então uma expressão. Ela possui um corpo, ela tem um lugar. Assim compreendida, a voz não pode se satisfazer de uma concepção desencarnada e monológica do sujeito. [...] A voz é diálogo. Com o outro, com a minha comunidade" ${ }^{26}$.

A voz torna-se, ao mesmo tempo, social e corporal, como observa Bourdieu: "Ela é comumente associada à impressão de uma regressão às relações arcaicas, aquela da infância e das relações familiares" ${ }^{27}$. As origens sociais estão aqui implicitamente envolvidas, afirmando sua influência, já discutida, sobre o bilíngue: trabalhar a voz e a prática da língua dita maternal, às vezes distanciada para o aproveitamento da segunda língua, mergulha no íntimo e evoca a memória escondida, mas também as vergonhas e medos herdados das primeiras gerações dos filhos de pessoas deslocadas, exiladas ou migrantes. A voz não é somente fonação, mas abrange largamente todo um arranjo provisório do corpo físico que se inscreve no corpo social.

“O que o teatro põe em jogo - e em questão - politicamente é a prática política de narrações sociais”"28. Nesse jogo a voz tem um papel determinante, tanto quanto a escuta, que nunca é passiva: da mesma maneira que falamos do gesto da voz na sua emissão, podemos falar do gesto da escuta. 
Transições do corpo à voz, à procura do outro • Graça dos Santos

A voz não se reporta como voz senão por uma escuta já envolvida em si mesma. Tal escuta não acarreta, por conseguinte, somente nossa percepção, mas todo o nosso corpo orientado estendido sobre ela. Há certo relevo perceptivo correspondente então a certo estado de corpo $^{29}$.

Nós deslizamos a voz como extensão do corpo físico para o corpo social - e, como tal, uma das experiências mais alienantes é a de se ter a sensação de não ser digno de escuta, pois, mesmo sem uma mensagem formulada, uma voz tende a se fazer ouvir como referência de um grupo social, ocupando um lugar político. Mas não esqueçamos que a atividade dramática - à qual são semelhantes os ateliês de idiomas em movimento - é também uma atividade lúdica, que se insere na dinâmica dos jogos simbólicos (jogos de imitação, jogos de ficção...) e, quando há manifestação da atitude lúdica, há acesso aos recursos criativos. Os processos assim postos em movimento permitem tanto a inversão do caminho associado à reminiscência das origens e o desapego que conduz para fora de si, quanto o começo do encontro do outro (da língua do outro) e também da própria alteridade. É então uma voz desconhecida, vinda de outro lugar e falante de uma língua desconhecida: "A voz vem ao lugar do que é propriamente indizível para o sujeito"s0.

\section{À PROCURA DO MILAGRE VOCAL}

Quando menciona seu trabalho para o palco, Peter Sellars mostra em que ponto revela, de forma mais intensa, o indivíduo na sua relação com o outro. "Como criar uma atmosfera tal que os atores venham a se descobrir eles mesmos, a apresentar facetas de sua personalidade das quais eles não são necessariamente orgulhosos e que não revelam sempre os seus melhores lados? Como criar um lugar onde possam ter a coragem de trabalhar com o que os desestabiliza?"31. É, a princípio, por um trabalho onde a voz é desconectada de todo o conteúdo falado ou expresso, que conseguimos liberar os participantes dos ateliês e que, rapidamente, se torna evidente que a presença "é a forma de ser do corpo na escuta visual e auditiva" ${ }^{32}$. A recusa de uma compreensão puramente intelectual dá lugar à expressão viva.

Tudo isso só é possível através de exercícios que permitem reaprender o corpo, a respiração, o gesto, o movimento, o deslocamento, a relação com as coisas, a dissociação da palavra do gesto, a relação com o grupo e seus integrantes. Quando damos nossa voz, não é o mundo que vem a nós, somos nós que vamos ao mundo ${ }^{33}$. Mas na origem de tudo habita a respiração, esse gesto indispensável ao milagre vocal, que executamos desde nosso nascimento. Os exercícios em ateliê permitem revelar o instrumento invisível que implementa a voz e são compostos de três partes: a reserva de ar com os pulmões e o diafragma; a "câmara", lugar onde é feita a transformação do ar em ondas sonoras graças às cordas vocais; e os pavilhões onde o ar se torna sonoro antes de ser modulado graças à faringe, à boca, às fossas nasais.

29. VANNI, Michel. Maladresses des voix 20 thèses militantes [Falta de jeito na voz - 20 teses militantes]. In: Multitudes, n. 42, automne 2000 p. 198.

30. MILLER, J. A. Jacques Lacan et la voix [Jacques Lacan e a voz]. Colloque d'lvry [Simpósio de Ivry]. In: La Lysimaque, 1995, p. 260. Apud VIVES, Jean-Michel. Pour une assomption sonore du sujet [Para uma suposição sobre o som]. Les Champs de la voix [Os campos da voz], Art et thérapie [Arte e terapia], n. 68-69, p. 105, dez. 1999

31. SELLARS, Peter. Etre acteur, jouer, agir [Ser um ator, atuar, agir]. In: FÉRAL, op. cit., p. 79-80.

32. STEIGER, op. cit., p. 120.

33. HINDENOCH, Michel. Le conte de la voix. Art et thérapie, cit., p. 10. 
comunicação \& educação • Ano XVII • número 2 • jul/dez 2012

\section{A VOZ, PORTA ABERTA PARA A EMOÇÃO}

Partidos em busca da voz e de sua teatralidade, entre teoria e prática, usamos nossa dupla experiência linguística e profissional e procuramos as passagens que, do corpo à voz, nos levam tanto em direção à língua dos outros quanto em direção à compreensão profunda de nossa história. Quando a linguagem é articulada, torna-se ao mesmo tempo o mestre e a ferramenta do pensamento, veículo de nosso imaginário. Enquanto temos, de nossa própria voz, apenas um eco abafado pela própria audição, é o ouvido do outro que possui dela a melhor percepção. A voz necessita ser ouvida, é vínculo entre o individual e o coletivo; reminiscência de memórias escondidas, é expressão tanto do ser social no seu relato ao grupo quanto do indivíduo no mais profundo de sua solidão.

Em sua busca do mistério da linguagem articulada, o foniatra Jean Abitbol indica que o comando do músculo das cordas vocais depende de um único nervo craniano, ao mesmo tempo sensorial e motor. "Ele permite modular as cordas vocais, ele as separa para respirar, ele as fecha para falar, ele cria a voz, ele permite retardar o ritmo cardíaco, aumentar nossa acidez gástrica. Ele conjuga a emoção da expressão verbal" ${ }^{\prime 4}$. Eis por que, então, a voz trai nosso $e u$ interior - esse $e u$ expandido do bilíngue na sua dupla percepção da voz e da língua, para quem a passagem do corpo à voz jamais é unívoca. Imitando a língua do outro bem de perto, seu desdobramento é próximo daquele realizado pelo ator quando se transforma em personagem. A situação pedagógica proporcionada pela expressão dramática aparece como ideal para modular o que se torna uma pedagogia do process ${ }^{35}$ vocal, em abertura e em direção à consciência de si e à afirmação da presença.

O corpo deve ser preparado e receptivo, mas isso não é tudo. A voz deve ser aberta e livre. As emoções devem ser abertas e livres. [...] a voz é assim passível de encontro autêntico porque ela permite exceder as inscrições de uma cultura particular. Uma língua não é, finalmente, senão traço de uma experiência do vivido, um código emocional - e o fato de pronunciá-la sem compreender o seu sentido concede a apreensão de emoções de natureza desconhecida. Quando nós deixamos passar através de nós mesmos as sílabas de uma linguagem estrangeira, nós somos atraídos em partes ignotas do nosso ser, de nosso corpo. A voz constitui eminentemente um caminho ideal de compreensão do outro em sua diferença ${ }^{36}$.

\section{REFERÊNCIAS BIBLIOGRÁFICAS}

ABDELILAH-BAUER, Barbara. Le défi des enfants bilingues. Grandir et vivre en parlant plusieurs langues [O desafio das crianças bilíngues. Crescer e viver em ambientes multilingues]. Paris: Editions La Découverte, 2006.

ABITBOL, Jean. L'odyssée de la voix [A Odisseia da voz]. Paris: Robert Laffont, 2005 . 
Transições do corpo à voz, à procura do outro - Graça dos Santos

BARBA, Eugenio. L'essence du théâtre [A essência do teatro]. In: FÉRAL, Josette. Les chemins de l'acteur, former pour jouer [Os caminhos do ator, treinados para atuar]. Montreal: Editions Québec Amérique, 2001.

BARRET, Giselle. Repères, Essais en éducation [Notas, questões em educação], Montréal, n. 7, 1986.

BENECH, Bernard. La parole offerte; quelques réflexions sur la voix au théâtre [O discurso oferecido; algumas reflexões sobre a voz no teatro]. Art et thérapie [Arte e terapia], n. 68/69, Les champs de la voix [Os campos da voz].

BERNARD, Michel; RYNGAERT, Jean-Pierre. L'improvisation [A improvisação]. In: LALLIAS, Jean-Claude; JACQUES, Lassalle; LORIOL, Jean-Pierre, Dir. Le théâtre et l'école. Histoire et perspective d'une relation passionnée [O teatro ea escola. História e perspectiva de uma relação passional]. Cahiers de l'ANRAT, Arles, Actes Sud, n. 11, 2002.

BOURDIEU, Pierre. Méditations pascaliennes [Meditações pascalianas]. Paris: Seuil, 1997. Apud ERARD, op. cit., p. 195.

CASTARÈDE, Marie-France. La voix et ses sortillèges [A voz e seus sortilégios]. Paris: Les belles lettres, 1991.

CHALENDON, Sorj. Le petit Bonzi [O pequeno Bonzi]. Paris: Bernard Grasset, 2005.

CORVIN, Michel. Dictionnaire encyclopédique du théâtre à travers le monde [Dicionário enciclopédico do teatro em todo o mundo]. Paris: Editions Bordas/ SEJER, 2008.

ERARD, Yves. Faire entendre sa voix [Faça ouvir a sua voz]. Multitudes, n. 42, automne 2000.

FLEISCHER, Alain. L'accent, une langue fantôme [O sotaque, uma língua fantasma]. Paris: Editions du Seuil, 2005.

HINDENOCH, Michel. Le conte de la voix. Art et thérapie, cit.

HUSTON, Nancy. Nord perdu [Norte perdido]. Arles: Actes Sud, 1999.

JOUVET, Louis. Le comédien désincarné [O ator desencarnado]. Paris: Flammarion/Champs, 2009.

MILLER, J. A. Jacques Lacan et la voix [Jacques Lacan e a voz]. Colloque d'Ivry [Simpósio de Ivry], La Lysimaque, 1995, p. 260. Apud VIVES, Jean-Michel. Pour une assomption sonore du sujet [Para uma suposição sobre o som]. Les Champs de la voix [Os campos da voz], Art et thérapie [Arte e terapia], n. 68-69, dez. 1999.

PAVIS, Patrice. Dictionnaire du théâtre [Dicionário do Teatro]. Paris: Armand Colin/VUEF, 2002.

RUNTZ-CHRISTIAN, Edmée. Enseignant et comédien, un même métier? [Professor e ator, uma mesma ocupação?]. Issy-les-Moulineaux: ESF Editeur, 2000. 
comunicação \& educação • Ano XVII • número 2 • jul/dez 2012

RYNGAERT, Jean-Pierre. Jouer, représenter (Pratiques dramatiques et formation) [Jogar, representar (práticas dramáticas e formação)]. Paris: CEDIC, 1985.

SELLARS, Peter. Etre acteur, jouer, agir [Ser um ator, atuar, agir]. In: FÉRAL, Josette, op. cit.

STEIGER, André. Le jeu comme transparence [O jogo como transparência]. In: FÉRAL, Josette. Les chemins de l'acteur, former pour jouer [Os caminhos do ator, treinado para atuar]. Montréal: Editions Québec Amérique INC, 2001.

VANNI, Michel. Maladresses des voix 20 thèses militantes [Falta de jeito na voz 20 teses militantes]. Multitudes, n. 42, automne 2000.

ZAEPFFEL, Alain. Quelques notes sur la déclamation [Algumas notas sobre a declamação]. In: LALLIAS, Jean-Claude; LASSALLE, Jacques; LORIOL, JeanPierre, Dir. Le théâtre et l'école. Histoire et perspective d'une relation passionnée [O teatro e a escola. História e perspectiva de uma relação passional]. Cahiers de l'ANRAT, Arles, Actes Sud, n. 11, 2002.

ZEKRI-HURSTEL, Régine. Un nouveau regard sur l'élève: langage, gestes et postures [Um novo olhar sobre o aluno; linguagem, gestos e posturas]. Rodez: Editions du Rouergue, 2001. 